\title{
Silvicultural squintings in a crystal ball
}

by

The Prophet Yad-yarrum

\section{Forum}

Rising demand for diminishing timber, imbalanced age-classes, overstocked undergraduate classes, increasing back-logs, plantation failures, tubed seedlings and a toilet paper shortage are easy to "backcast' in 1974; but what is forecast for 1984, the year of Orwell's predictions...

It is hazardous to attempt to foretell the future squinting at the slurred scenes in my silvicultural sphere. When the prophecies of the last silvical-soothsayer, a 'Jolly Green Giant' in his day, proved wrong he was pruned, felled and planted. This does not augur well for 'Green Survival' should my prophecies fare less well than his.

So hearken, as in a trance I clothe the branches of the future with leaves of wisdom. Will my leaves be as green in 1984 as now or will they wither in the augurer's autumns as I prophesy...

\section{Prophecies}

Beware ye! The silvicultural shaz is sure to stay.

"Wedgelings will be dying, diameters falling,

stock will be stashed by robot machines,

brown will be up and green will be down,"

Virgin beware! Only memories of you will linger.

"The Koehrings will pluck you and pluck you and pluck you,

and the wind it will topple your last standing trees,

and green will be down and brown will be up."

Backlog prepare! This is your time, now you are truly needed.

"Balsam bespeckled brush of alder, birch and poplar, you have had your chips in the whirling teeth of the tree-eater,

white ones for paper, green and brown in a spray up and down."

Foresters behold! No longer shepherds of great oaks and pines.

"Intensive culture yours, max NPP: your concepts now are

Young's 'whole tree' and Schreiner's 'mini rotation' the

densest, buggiest puckerbrush in all creation."

Trees quiver! The joys of wild pollination are ended.

"Promiscuous monarchs of the forest tremble, you will be shot at, scioned and artificially inseminated, your children will be hulking heterotic foreign bastards regimented in rows."

Soils beware! You may be needed if you are good, otherwise abandoned.

"Rest poor soils now is not your time, deep soils shudder you will be augered, tested, tilled, amended and asked to suckle the brown so the green will grow up and the roots down,"

Silviculture behold! Unclear your cut, strip and be modified.

Rust ye O'pads and chains, power flails will flog away your duff, so seeds 'atomic' or plugs pregnant with super spruce and pine will shout with one accord, "Up with the green and down with brown."

\section{Finis}

Forest futures fortold from writings on the Woodsman's Ouija Board 